\title{
Making the case for procedural justice: Employees thrive and work hard
}

\author{
Minseo Kim ${ }^{1}$ and Terry A. Beehr ${ }^{2}$ \\ ${ }^{1}$ Centre for Work, Organisation and Wellbeing, Griffith University, Brisbane, Queensland, 4111, \\ Australia \\ ${ }^{2}$ Department of Psychology, Central Michigan University, Mount Pleasant, Michigan 48859, \\ U.S.A.
}

Some of these data were presented at the April 2018 Society for Industrial and Organizational Psychology annual meeting in Chicago, Illinois.

\section{Author biographies}

Minseo Kim is a Research Fellow at the Centre for Work, Organisation and Wellbeing, Griffith University. She received her $\mathrm{PhD}$ from Central Michigan University with a major in Industrial and Organizational Psychology. Her research interests include occupational stress, leadership, motivation, job crafting, and employee well-being.

Email: minseokim0331@gmail.com

Terry A. Beehr is a Professor of Psychology and member of the I/O Psychology faculty at Central Michigan University. His research interests include occupational stress, leadership, motivation, careers, and retirement. Email: beehr1ta@cmich.edu 


\title{
Making the case for procedural justice: Employees thrive and work hard
}

\begin{abstract}
Purpose - Procedural justice consists of employees' fairness judgments about decision-making processes used to allocate organizational rewards and has been linked to positive work outcomes. We drew from social exchange and reciprocity theories to examine a model proposing psychological empowerment and organization-based self-esteem (OBSE) as two psychological processes explaining the relationship of procedural justice with employees' work effort and thriving.
\end{abstract}

Design/methodology/approach - Three-waves of data with one-month time lags were obtained from 346 full-time U.S. employees. Structural equation modeling tested the hypotheses. Findings - Results supported the model. Procedural justice at Time 1 was positively related to psychological empowerment and OBSE at Time 2, which both led to employees' work effort and thriving at Time 3.

Originality/value - The study provided a theoretical explanation for procedural justice resulting in better work effort and thriving: Psychological empowerment and OBSE may provide a bridge for the effects of procedural justice on employee work effort and thriving. Keywords Procedural justice, Psychological empowerment, Organization-based self-esteem, Work effort, Thriving at work 
Organizational justice, employees' subjective perceptions of how fairly they are treated at work, has long been of interest to researchers and practitioners because of its positive effects on employee affect, attitudes, and behaviors (Cohen-Charash and Spector, 2001; Colquitt et al., 2013). Among multiple types of justice, two types traditionally predominated justice research and theory. Distributive justice, derived from principles of equity theory (Adams, 1963), is the perceived fairness of allocations of organizational outcomes (e.g., rewards) related to the contributions made by employees. The other main type of justice, procedural justice, is the focus of the present study; it consists of employees' perceived fairness of the decision-making processes used to determine those outcome distributions (Colquitt, 2001) and is explained by social exchange theory (Homans, 1958).

Based on social exchange theory (Homans, 1958), perceived organizational support and trust concepts are often examined as explanations for effects of justice (Rupp et al., 2014). The reciprocity inherent in social exchange theory maintains when one party (e.g., the organization) provides something valuable to another (e.g., the employee), the second party feels an obligation to reciprocate by returning something of value, completing the exchange. We tested a model of exchange and reciprocity in which the organization provided fair procedures and practices — an equitable and just setting in which to work. In exchange, employees provided higher work effort and were able to grow and develop (thrive) at work. However, in order to elaborate this "blackbox" version of the theory, we were concerned with explaining why this effect occurs: Which intermediate variables transmit the effect of procedural justice to motivate reciprocation?

We proposed that employees' intrinsic motivation factors can account for links from justice to both criterion variables. The model (Figure 1) thus proposes forms of employee motivation explain these effects of justice. Motivation relates to employees' initiating task- 


\section{MOTIVATIONAL PROCESSES FOR THE EFFECT OF JUSTICE 4}

related behaviors and helps determine their direction, intensity, and duration (Latham and Pinder, 2005). However, few studies empirically examined motivation variables as a potential consequence of justice (e.g., general intrinsic motivation was an intermediate outcome of procedural justice in Zapata-Phelan et al., 2009).

More specifically, we propose dual motivational variables. As explained in Kim and Beehr (2018) and Thomas and Velthouse (1990), job-related motivation of psychological empowerment consists of experiencing meaningful work, competence, self-determination, and impact (Spreitzer, 1995), while self-related motivation of individuals' organization-based selfesteem (OBSE) represents employees' beliefs of their worthiness and capabilities as organizational members (Pierce and Gardner, 2004). Organizational justice affects positive affect and emotion (Cropanzano et al., 2000), which is relevant to employees' motivation to shape their work roles through being empowered (Spreitzer, 1995; Thomas and Velthouse, 1990). Justice also signals employees that they are valued by their organizations, thereby affecting their selfworth. Despite the assumed connection between justice and intrinsic motivation, little empirical research has provided a motivation-based explanation in one overall model.

We propose effort and thriving at work as distal consequences of justice perceptions. Work effort, the energy employees put into their jobs, is important for goal attainment (De Cooman et al., 2009). Additionally, work effort may be a more proximal outcome of motivation coming from employees' perceptions of justice, compared to more final results-oriented measures (Kuvaas et al., 2016). Thriving at work, a construct capturing employees’ psychological well-being (sense of vitality and growth), is linked to important outcomes, including attitudes, performance, positive health, and careers (Porath et al., 2012; Walumbwa et al., 2018). We propose thriving is also a relevant outcome for procedural justice. 


\section{MOTIVATIONAL PROCESSES FOR THE EFFECT OF JUSTICE 5}

Procedural justice represents organizational procedures and practices in employeeorganization exchanges. It has strong relationships with employee responses such as job performance (meta-analysis; Cohen-Charash and Spector, 2001). Motivation is a direct contributor to performance and therefore it would have positive associations with the study's two intrinsic motivation indicators. Furthermore, to clearly examine the potential unique effects of procedural justice, our analyses held distributive justice constant.

\section{Contribution}

Overall, we aimed to test a new model developed from exchange theory, wherein organizational treatment of employees in a just manner is exchanged for the employees' work effort and thriving, and the process is completed through motivational mechanisms (psychological empowerment and OBSE). Previous studies of justice examined variables related to work effort (e.g., performance outcomes), but the examination of employee thriving as a result of this process is new. Consequently, we extend outcomes of justice and contribute a theoretical explanation for why procedural justice can result in increased work effort and the new outcome, thriving: Two intrinsic motivational constructs, psychological empowerment and OBSE, help transfer effects of procedural justice to increased work effort and employee thriving.

\section{Hypotheses}

Procedural justice refers to how allocation decisions are made and is fostered when decision-making processes follow certain rules, including accurate information, consistency over time, and prevailing ethical standards (Leventhal et al., 1980). Procedural justice also allows employees some control/input about decision-making and about final outcomes in the form of decision influence (Thibaut and Walker, 1978). Therefore, procedural justice is related to 


\section{MOTIVATIONAL PROCESSES FOR THE EFFECT OF JUSTICE 6}

employees' positive emotions (Cropanzano et al., 2000), which could influence employees' motivation (Zapata-Phelan et al., 2009).

We thus propose procedural justice may affect two psychological states functioning as forms of employee motivation. One, psychological empowerment, consists of meaning, competence, self-determination, and impact (Seibert et al., 2011), reflecting perceptions about work and one's ability to influence work roles (Spreitzer, 1995). Relationships between employees' perceptions of procedural justice and psychological empowerment is not wellestablished, but some previous findings imply procedural justice enhances perceptions of psychological empowerment. For example, sociopolitical support, access to information and resources, and participative work environments, which should relate to procedural justice, had positive relationships with psychological empowerment (Maynard et al., 2013; Spreitzer, 1995). Herrenkohl et al. (1999) found general perceptions of fairness were key elements distinguishing more empowered from less empowered groups. Therefore, fair organizational procedures should positively relate to employees' psychological empowerment.

Psychological empowerment also helps explain work effort. Employees exchange effort for experiences of psychological empowerment. Studies demonstrated that psychological empowerment related positively to constructs associated with work effort, including measures of discretionary behavior and performance (Pigeon et al., 2017; Seibert et al., 2011). Thus, we predict when employees feel psychologically empowered due to experiencing justice, they will reciprocate with work effort.

Another, newer, anticipated consequence of psychological empowerment is thriving at work, a positive psychological state including a sense of vitality and growth through learning. The vitality in thriving consists of positive energy, and learning enhances a sense of competence 


\section{MOTIVATIONAL PROCESSES FOR THE EFFECT OF JUSTICE 7}

and efficacy. We expect psychological empowerment to trigger employees' thriving.

Specifically, empowered employees feel competent and that their work is meaningful (Spreitzer, 1995). Accordingly, they focus more on everyday work and thrive at work. In addition, psychologically empowered employees seek stimulating roles or challenging goals, so that work is more intrinsically exciting. Lastly, empowered employees perceive themselves as having control over their work environment, self-determination, and competence (Spreitzer, 1995), and they tend to engage in active learning to benefit the organization (Spreitzer and Porath, 2014).

Overall, fairness of procedures in the workplace enables employees to experience psychological empowerment, which in turn fosters thriving at work.

H1. Psychological empowerment mediates the positive exchange of procedural justice for (a) work effort and (b) thriving at work.

A second motivational mechanism explaining effects of procedural justice on employee's effort and thriving is organization-based self-esteem (OBSE). It is another intrinsic motivation construct but is a more self-related motivation. OBSE refers to employees' beliefs about their value and competence as organizational members (Pierce and Gardner, 2004). OBSE is affected by the work environment and in turn affects various outcomes, including job involvement, performance, and well-being (Bowling et al., 2010). We propose employees' self-esteem at work will be positively influenced by fairness of procedures. Experienced procedural justice can be an indicator of employees' respect from one's organization (McAllister and Bigley, 2002). Respect is conceptually inherent in justice and theoretically increases self-esteem (e.g., Grover, 2014). When employees perceive they are treated fairly and respectfully, their OBSE is enhanced. In contrast, if employees feel they are treated more poorly than they think they deserve due to the process used to produce reward distributions, evaluations of their work-related self-worth will 


\section{MOTIVATIONAL PROCESSES FOR THE EFFECT OF JUSTICE 8}

decrease. That is, procedural justice may convey to employees that they are valued organization members; therefore, it should promote employees' OBSE, for which the employees can reciprocate the effects of justice with improved work efforts.

Although no previous research directly examined work effort as an OBSE outcome, we expect OBSE to improve employees' efforts and behaviors (Pierce and Gardner, 2004); employees are willing to invest more in their work roles, leading to higher work efforts. Furthermore, individuals behave in ways that enhance or maintain their self-esteem (Korman, 1976), and they can strive for esteem by demonstrating their value in the workplace. Therefore, high OBSE makes employees more willing to increase their work efforts.

We also argue that OBSE will contribute positively to employees' thriving at work. Because OBSE reflects high self-competence and organizational value, employees feeling OBSE actively engage in tasks and strive for effective functioning, which generates vitality and enhances possibilities for learning. Additionally, individuals believing they are worthy are likely to provide social support for other organizational members and exhibit cooperative behaviors, leading to increased energy (Bowling et al., 2010; Spreitzer et al., 2005). Summarizing, we suggest that procedural justice develops employees' OBSE, which in turn relates to their work effort and thriving.

H2. Organization-based self-esteem mediates the positive exchange of procedural justice for (a) work effort and (b) thriving at work.

\section{Method}

The sample were full-time U.S. employees in various industries (e.g., health, education, finance, information technology etc.). They were recruited through MTurk, a commercial service paying respondents for completing cognitive tasks including surveys. We restricted participation 


\section{MOTIVATIONAL PROCESSES FOR THE EFFECT OF JUSTICE 9}

to employees with at least a $95 \%$ approval rating in prior assignments, as recommended by methodological studies (e.g., Mason and Suri, 2012). Methodological research shows MTurk workers in the U.S. read survey instructions carefully and are a broad sample of the U.S. population (e.g., Keith et al., 2017). MTurk data are as good or better than those from two professional marketing services (e.g., Qualtrics) in terms of variables' reliability and passing attention checks, suggesting MTurk participants read more carefully (Kees et al., 2017). Goodman et al.'s (2013) review concluded MTurk produces reliable results with few or no different biases from community samples, and Keith et al. (2017) concluded there is no clear evidence that MTurk data are any less accurate than other common data sources, laying to rest any concerns about data quality.

We collected data at three time points with one-month intervals, reducing effects of common methods (Podsakoff et al., 2012). We also employed recommended quality-control techniques (Cheung et al., 2017). If participants provided the same answers across reversed and non-reversed items and failed to choose a correct answer on general attention-check questions (e.g., the sky is usually blue; Disagree-Agree) their data were eliminated. We also excluded cases with apparently low effortful responding; participants selecting many of the same responses $(80 \%)$, whose answers were outliers, or who finished the survey four times faster than the mean.

At Time 1, 570 full-time US employees answered the survey; 43 were eliminated due to attention checks. Of these, 474 responded one month later (Time 2); we eliminated 28 cases for low-effort responding and failing attention checks. The remaining 446 respondents were contacted one month later (Time 3). Of these, 358 responded; 12 cases were deleted due to mismatched codes and multivariate outliers. Analyses with original data versus without outliers showed similar results; analyses reported here were from a final sample of 346 (60.7\% retention 
rate from the initial sample): $54.9 \%$ were male, $79.2 \%$ white, and $67.0 \%$ had at least a bachelor's degree. Their ages averaged 35.27 years $(S D=9.60)$, they worked about 40.67 hours per week $(S D=7.75)$, and their organizational tenure was 6.56 years $(S D=5.63)$. About $61.2 \%$ were front-line employees, $16.8 \%$ were supervisors, $16.2 \%$ were managers, and $5.8 \%$ were upper-managers or executives.

We examined the representativeness for the Time 3 sample of the Time 1 and Time 2 samples with logistic regression (Goodman \& Blum, 1996). We used demographics as well as procedural and distributive justice variables available at Time 1. Only age differed from Time 1 to Time 3; it increased from $M=34.37(S D=9.33)$ to $M=35.27(S D=9.60)$. Therefore overall, participant loss appears random across time points; there was no severe attrition bias.

\section{Measures}

Time 1 measures included the predictor variable, procedural justice, and demographics; Time 2 measured the two mediators, psychological empowerment and OBSE; and the Time 3 survey measured the two outcomes, work effort and thriving. We measured the control variable, distributive justice, at Time 1.

Procedural Justice (Moorman, 1991) was measured using 6 items $(\alpha=.92)$. An example item is "Procedures in your organization provide useful feedback regarding the decision and its implementation," rated from 1 (strongly disagree) to 6 (strongly agree).

Psychological Empowerment (Spreitzer, 1995) was assessed using 12-item $(\alpha=.89)$ Empowerment Scale composed of three items for each of four dimensions: meaning, competence, self-determination, and impact. Example items include "The work I do is very important to me" (meaning), "I am confident about my ability to do my job" (competence), "I have significant autonomy in determining how I do my job" (self-determination), and "I have 


\section{MOTIVATIONAL PROCESSES FOR THE EFFECT OF JUSTICE 11}

significant influence over what happens in my department" (impact), which rated from 1 (strongly disagree) to 7 (strongly agree).

Organization-Based Self-Esteem (Pierce et al., 1989) was measured using 10 items $(\alpha=$ .93). A sample item is "I am valuable in this organization," rated from 1 (strongly disagree) to 7 (strongly agree).

Work Effort (Kuvaas \& Dysvuj, 2009) was measured using four items $(\alpha=.85)$. A sample item is "I often expend extra effort in carrying out my job," rated from 1 (strongly disagree) to 5 (strongly agree).

Thriving at Work (Porath et al., 2012) was measured with 10 items $(\alpha=.93)$ consisting of two components, vitality and learning. Example items include "I feel alive and vital" and "I find myself learning often" rated from 1 (strongly disagree) to 5 (strongly agree).

We considered three potential control variables. The first was distributive justice as another social exchange variable, and because empirically, it is usually related to procedural justice (e.g., Colquitt et al., 2013; Hauenstein, McGonigle, and Flinder, 2001), which could have contaminated the results. Distributive justice (Moorman, 1991) was measured using 5 items. An example item is "You are fairly rewarded for the amount of effort you put forth," rated from 1 (strongly disagree) to 6 (strongly agree). Second, we treated gender as another potential control variable because of some empirical evidence that procedural justice is more important for women (e.g., Sweeney \& McFarlin, 1997). Finally, we examined managerial position by eliminating 20 respondents with higher-level managerial positions $(5.8 \%)$ in order to control for their influence, because they are involved in decision-making procedures.

\section{Results}


MOTIVATIONAL PROCESSES FOR THE EFFECT OF JUSTICE 12

Table 1contains means, standard deviations, reliabilities, and correlations. Correlations for proposed model paths were significant. Procedural justice was positively related to the psychological empowerment $(r=.54, p<.01)$ and OBSE $(r=.36, p<.01)$. Psychological empowerment was positively related to work effort $(r=.36, p<.01)$ and thriving $(r=.40, p<$ $.01)$, and OBSE was also positively related to work effort $(r=.34, p<.01)$ and thriving $(r=.36$, $p<.01)$.

Hypotheses and model testing

Structural equation modeling (SEM; LISREL 8.8 Jöreskog and Sörbom, 2006) tested model fit and hypotheses. Following recommendations (Matsunaga, 2008), item-parceling was used for the unidimensional constructs to form latent variables; parcels are more reliable and normally distributed than single items (Bandalos, 2002), and they reduce model complexity (Nasser and Takahashi, 2003), having more total scale points (Rushton, Brainerd, and Pressley, 1983). We used random item parceling, which helps reduce measurement error (Bagozzi and Edwards, 1998). The 6-item procedural justice measure had three indicators. The 10-item OBSE measure had three indicators (two parcels of three items and one parcel of four items). Work effort had only four items, which served as indicators. Distributive justice had five items, also used as indicators without parceling. Two variables had subscales, psychological empowerment and thriving; their subscales were used as indicators. The confirmatory factor analysis (CFA) or measurement model indicated satisfactory fit, $\chi^{2}(174, N=346)=415.04, p<.01$; CFI $=.98$; IFI $=.98 ; \mathrm{NNFI}=.97 ; \mathrm{RMSEA}=.06$. Because the two criteria, work effort and thriving at work, were somewhat highly correlated $(r=.64, p<.01)$, we tested the fit of a two-factor model for them. That CFA produced good fit, $\chi^{2}(8, N=346)=28.45, p<.01 ; \mathrm{CFI}=.99 ; \mathrm{IFI}=.99 ; \mathrm{NNFI}=$ .97 ; RSEA $=.09$, showing evidence for their discriminant validity. 
The hypothesized model (Figure 1) fit the data well, $\chi^{2}(180, N=346)=583.87, p<.01$; $\mathrm{CFI}=.96 ; \mathrm{IFI}=.96 ; \mathrm{NNFI}=.95 ; \mathrm{RMSEA}=.08$. Regarding model paths, procedural justice was positively related to psychological empowerment $(\beta=.59, p<.01)$ and $\operatorname{OBSE}(\beta=.30, p<.01)$; psychological empowerment was positively related to work effort $(\beta=.31, p<.01)$ and thriving $(\beta=.47, p<.01)$. OBSE was also positively related to the two criteria, work effort $(\beta=.32, p<$ $.01)$ and thriving $(\beta=.18, p<.01)$. Overall, the SEM results supported the proposed model.

Control variables. Regarding the control variables, distributive justice was significantly related to the variables in the model and was therefore included in all model analyses. Gender had a weak but significant correlation with only psychological empowerment $(r=.13, p<.05)$. Analyses with both distributive justice and gender as control variables showed that gender did not have significant relationships with procedural $(\beta=.06, p=.26)$ and distributive justice $(\beta=$ $.01, p=.83)$, and the SEM results remained unchanged after controlling for gender. We also reran the model after eliminating 20 cases with a higher-level managerial position $(5.8 \%)$ from the analysis, and path coefficients were not appreciably changed from the original model. Therefore, controlling for position and gender did not affect our conclusions.

\section{Alternative model testing}

Alternatively, procedural justice might have simpler, direct effects on effort and thriving. Therefore, we tested an alternative model adding two direct paths from procedural justice to the outcomes (Figure 2). The alternative model did not improve fit indices however, $\chi^{2}(178, N=$ $346)=584.41, p<.01 ; \mathrm{CFI}=.96 ; \mathrm{IFI}=.96 ; \mathrm{NNFI}=.95 ; \mathrm{RMSEA}=.08$. The additional two direct paths were not significant, and the model fit was not significantly improved $\left(\Delta \chi^{2}[2]=0.54\right.$, $p=.08)$, indicating that psychological empowerment and OBSE were likely important states 
transmitting effects of procedural justice to employee's effort and thriving, supporting the hypotheses.

Table 2 presents standardized direct, indirect, and total effects from LISREL and shows no direct effects anywhere in the model, providing strong support for mediation. For example, there is an indirect effect of procedural justice on work effort $(.35, p<.01)$ mediated by psychological empowerment (.60 x .43) and OBSE (.31 x .32) (for calculation rules, see Bollen, 1989). The influence of procedural justice on work effort is therefore $.22, p<.01$. Comparing the magnitudes of these effects indicates that the effects of psychological empowerment and OBSE on work effort are stronger than the total effect of procedural justice on work effort.

\section{Discussion}

Although research linked justice to some important outcomes (Colquitt et al., 2013), little attempt has been made to examine how perception of procedural justice relates to employees' effort and thriving at work. By integrating justice and themes based on social exchange theory (e.g., Homans, 1958; Rupp et al., 2014), we investigated part of the black-box of social exchange in the workplace. Procedural justice appears linked to employees' effort and thriving by mediation of two intrapsychic constructs, psychological empowerment and OBSE. The results suggested employees were more likely to feel empowered and self-worth in procedurally fair work environments. Psychological empowerment and OBSE can be considered intrinsic motivation variables that resulted in greater work effort. They also contributed to thriving, a sense of vitality and learning at work. Procedural justice was not linked directly to employees' effort and thriving, however. Together, findings provided insight into psychological mechanisms through which perceptions of procedural justice may influence employees' work effort and thriving. Employees' psychological states evoked by fair treatment are more proximal 


\section{MOTIVATIONAL PROCESSES FOR THE EFFECT OF JUSTICE 15}

antecedents fostering work effort and thriving than organizational fairness contexts (procedural justice) are. Another major contribution is to extend research on organizational justice by adding a new outcome - thriving at work.

\section{Implications for theory and research}

Adding thriving as criteria in organizational justice theory is recommended for future

research, and mediators of psychological empowerment and OBSE are also promising for future justice research. We focused on procedural justice, showing this type of justice can result in psychological states transmitting its effects to important outcomes. The outcome of work effort in relation to justice derives from social exchange theory (Rupp et al., 2014); employees being treated fairly reciprocate by working harder, thereby repaying the organization for treating them well. Results showed this reciprocation is powered by psychological feelings of empowerment and OBSE. In contrast, injustice could result in exchanges of negative outcomes. For example, Klaussner (2014) developed social exchange and organizational (in)justice theory explaining how exchanges can lead to the development of abusive supervision.

There may be another instance of reciprocal exchange involved, one not proposed in the model. Thriving can enhance employees' well-being and development, and in return for this organization-aided self-enhancement, the employee might again reciprocate with further effort. The correlation between thriving and effort $(r=.64)$ is consistent with a model suggesting thriving could lead to greater work effort. Future research could test elaborated models taking this possibility into account.

\section{Implications for management}

Previous research showed organizational justice can be useful by resulting in favorable outcomes, including organizational commitment, organizational citizenship behavior, and (less) 
counterproductive work behavior (meta-analysis by Colquitt et al., 2013). In addition, however, the present study highlights the role of justice in promoting psychological states that result in greater effort that employees can use to do their jobs better. Because justice can also enhance employees' well-being, management efforts to implement empowering leadership styles can help enhance the state of employees as well as the organization.

The model in our study therefore has several practical management implications. Because employees' work effort and thriving are essential states with relevant organizational outcomes, managers should strive to create and maintain the level of energy and passion employees use in their work efforts. Given our results, managers should pay attention to the level of formal procedural justice in the organization by sharing information and offering feedback on decisionmaking processes transparently. This entails managers and immediate supervisors listening to employees' opinions and involving employees from various groups in the process of decisionmaking to improve and maintain procedural justice.

In addition, regularly updating sets of procedures used in personnel assignments, promotions, and reward systems are occasionally necessary, and management should take these actions with justice principles in mind. In order to guide and evaluate these updates, employee surveys can monitor their perceptions of and reactions to those procedures. Such assessments are feasible ways to gauge employees' preferences and their satisfaction levels, as well as to assess the organization's justice practices and procedures.

Procedural justice derives from perceptions that organizations' resource allocations are consistent and accurate, unbiased, correctable if necessary, take into account stakeholders' concerns, and based on ethical norms (Leventhal, 1980). These procedural justice principles can be incorporated into supervisory training and human resources policies, promoting organizations 
as just places to work. Supervisors are important agents in developing employees' perceptions of justice, because they represent the organization (e.g., Karam et al., 2019). Therefore, training and encouraging managers/supervisors to treat employees fairly would help to foster a just and productive work environment. Our findings showed links of organizational procedural justice with employee's work effort and thriving that they are facilitated by psychological empowerment and OBSE. This implies organizations implementing transparent and fair decision-making procedures result in employees feeling empowered and perceiving themselves as important organizational members, encouraging more work effort and experiencing psychological wellbeing.

\section{Limitations and future research}

This study had some limitations. Although we measured variables at separate times in a sequence matching the proposed model, the study design does not allow as strong an inference about causality as some other designs could (e.g., experimental designs manipulating justice). Because of the order of the measurements, however, reverse causality is less plausible empirically. Theoretically, reversed causality is also less plausible, because it is more difficult to argue that employee thriving should increase procedural justice.

The different times of measurement helped to reduce effects of common method variance (Podsakoff et al., 2012); to further minimize problems related to same-source bias, work effort could be assessed by managers or coworkers in future research. Moreover, we examined the proposed model only at the individual level and focused on consequences of procedural justice. Future research could adopt a multilevel design and explore organizational antecedents of employees' procedural justice perceptions. 
Another avenue for future research is to test particular leadership styles promoting autonomy-supportive environments (e.g., empowering leadership) interact with procedural justice or the two psychological constructs (empowerment and OBSE) in predicting employee effort and thriving. Many organizations increasingly use leadership practices providing delegation, autonomy, responsibility, and development to enable or encourage employees to focus on task accomplishment (Kim et al., 2018). Therefore, future research can examine empowering leadership as a boundary condition enhancing positive effects of justice on employee outcomes.

The present study focused on one type of justice, procedural justice, and the question remains whether other justice facets can also result in greater work effort and thriving by employees - and if so why (i.e., do some specific variables transfer the effects of other types of justice to these outcomes?). For example, for a very specific type of justice, interpersonal justice, would motivational variables explain its effects, or would more interpersonal process variables be necessary to transfer its effects?

Future research might test propositions including different outcomes for interpersonal justice, with reciprocity theory (Gouldner, 1960; Rupp et al., 2014) proposing that interpersonal justice might have its effects through different intermediate variables such as organizational citizenship behaviors directed toward helping other people in the workplace (reciprocity for being treated well by others). Finally, we focused on outcomes that benefit the organization and employees in the work domain, but future research could examine spillover effect of favorable states (psychological empowerment and OBSE) from work to non-work lives. For example, employees' general well-being outcomes such as flourishing and work-family relationship may be affected by employees' positive work experiences. 


\section{Conclusion}

In sum, our study advances knowledge on how organizational justice may influence employees' thriving and work effort. It highlights the central role of psychological empowerment and OBSE as psychological mechanisms explaining relationships between procedural justice and employee outcomes. By creating fair workplaces where employees are empowered and feeling OBSE, organizations will enhance both employees' effort and thriving. 


\section{References}

Adams, J.S. (1963), “Toward an understanding of inequity”, Journal of Abnormal Psychology, Vol. 67 No. 5, pp. 422-436.

Bagozzi, R.P. and Edwards, J.R. (1998), “A general approach for representing constructs in organizational research", Organizational Research Methods, Vol. 1 No. 1, pp. 45-87.

Bandalos, D.L. (2002), “The effects of item parceling on goodness-of-fit and parameter estimate bias in structural equation modeling”, Structural Equation Modeling, Vol. 9 No. 1, pp. 78-102.

Bollen, K.A. (1989). Structural equations with latent variables. Newbury Park, CA: Sage.

Bowling, N.A., Eschleman, K.J., Wang, Q., Kirkendall, C. and Alarcon, G. (2010), “A metaanalysis of the predictors and consequences of organization-based self-esteem", Journal of Occupational and Organizational Psychology, Vol. 83 No. 3, pp. 601-626.

Cheung, J.H., Burns, D.K., Sinclair, R.R. and Sliter, M. (2017), “Amazon Mechanical Turk in organizational psychology: an evaluation and practical recommendations", Journal of Business and Psychology, Vol. 32 No. 4, pp. 347-361.

Cohen-Charash,Y. and Spector, P.E. (2001), “The role of justice in organizations: a metaanalysis”, Organizational Behavior and Human Decision Processes, Vol. 86 No. 2, pp. 278-321.

Colquitt, J.A., Scott, B.A., Rodell, J.B., Long, D.M., Zapata, C.P., Conlon, D.E. and Wesson, M.J. (2013), "Justice at the millennium, a decade later: a meta-analytic test of social exchange and affect-based perspectives", Journal of Applied Psychology, Vol. 98 No. 2, pp. 199-236. 
Cropanzano, R., Weiss, H.M., Suckow, K.J. and Grandey, A.A. (2000), "Doing justice to workplace emotion", in Ashkanasy, N.M., Hartel C.E.J. and Zerbe, W.J. (Eds), Emotions in the workplace: Research, theory, and practice, Quorum Books, Westport, CT, pp. 4962.

De Cooman, R., De Gieter, S., Pepermans, R., Jegers, M. and Van Acker, F. (2009), "Development and validation of the Work Effort Scale", European Journal of Psychological Assessment, Vol. 25 No. 4, pp. 266-273.

Goodman, J.K., Cryder, C.E. and Cheema, A. (2013), "Data collection in a flat world: the strengths and weaknesses of Mechanical Turk samples", Journal of Behavioral Decision Making, Vol. 26 No. 3, pp. 213-224.

Goodman, J.S. and Blum, T.C. (1996), “Assessing the non-random sampling effects of subject attrition in longitudinal research", Journal of Management, Vol. 22 No. 4, pp. 627-652.

Gouldner, A.W. (1960), “The norm of reciprocity: a preliminary statement”, American Sociological Review, Vol. 25 No. 2, pp. 161-178.

Grover, S.L. (2014), “Unraveling respect in organization studies”, Human Relations, Vol. 67 No. 1, pp. 27-51.

Hauenstein, N.M., McGonigle, T., and Flinder, S.W. (2001), “A meta-analysis of the relationship between procedural justice and distributive justice: implications for justice research", Employee Responsibilities and Rights Journal, Vol. 13 No. 1, pp. 39-56.

Herrenkohl, R.C., Judson, G.T. and Heffner, J.A. (1999), “Defining and measuring employee empowerment", The Journal of Applied Behavioral Science, Vol. 35 No. 3, pp. 373 389. 
Homans, G.C. (1958), "Social behavior as exchange”, American Journal of Sociology, Vol. 63 No. 6, pp. 597-606.

Jöreskog, K.G. and Sörbom, D. (2006), LISREL 8.8 [computer software]. Lincolnwood, IL: Scientific Software International.

Karam, E.P., Hu, J., Davison, R.B., Juravich, M., Nahrgang, J.D., Humphrey, S.E., and Scott DeRue, D. (2019), “Illuminating the 'Face' of justice: a meta-analytic examination of leadership and organizational justice”, Journal of Management Studies, Vol. 56 No. 1, pp. 134-171.

Kees, J., Berry, C., Burton, S. and Sheehan, K. (2017), “An analysis of data quality: professional panels, student subject pools, and Amazon's Mechanical Turk", Journal of Advertising, Vol. 46 No. 1, pp. 141-155.

Keith, M.G., Tay, L. and Harms, P.D. (2017), “Systems perspective of Amazon Mechanical Turk for organizational research: review and recommendations”, Frontiers in Psychology, Vol. 8, pp. 1359.

Kernis, M.H., Brockner, J. and Frankel, B.S. (1989), "Self-esteem and reactions to failure: the mediating role of overgeneralization", Journal of Personality and Social Psychology, Vol. 57 No. 4, pp. 707-714.

Kim, M. and Beehr, T.A. (2018), “Challenge and hindrance demands lead to employees' health and behaviours through intrinsic motivation", Stress and Health, Vol. 34 No. 3, pp. $367-$ 378.

Kim, M., Beehr, T.A. and Prewett, M.S. (2018), "Employee responses to empowering leadership: a meta-analysis", Journal of Leadership \& Organizational Studies, Vol. 25 No. 3, pp. 257-276. 
Klaussner, S. (2014), "Engulfed in the abyss: the emergence of abusive supervision as an escalating process of supervisor-subordinate interaction", Human Relations, Vol. 67, No. 3, pp. 311-332.

Korman, A.K. (1976), "Hypothesis of work behavior revisited and an extension”, Academy of Management Review, Vol. 1 No. 1, pp. 50-63.

Kuvaas, B., Buch, R., Gagné, M., Dysvik, A. and Forest, J. (2016), “Do you get what you pay for? Sales incentives and implications for motivation and changes in turnover intention and work effort", Motivation and Emotion, Vol. 40 No. 5, pp. 667-680.

Kuvaas, B. and Dysvik, A. (2009), "Perceived investment in employee development, intrinsic motivation and work performance", Human Resource Management Journal, Vol. 19 No. 3, pp. 217-236.

Latham, G.P. and Pinder, C.C. (2005), "Work motivation theory and research at the dawn of the twenty-first century”, Annual Review of Psychology, Vol. 56, pp. 485-516.

Leventhal, G.S. (1980), "What should be done with equity theory?”, in Gergen, K.J., Greenberg, M.S. and Willis, R.H. (Eds), Social exchange: advances in theory and research and theory, New York, Plenum, pp. 27-55.

Leventhal, G.S., Karuza, J. and Fry, W.R. (1980), "Beyond fairness: a theory of allocation preferences", Justice and Social Interaction, Vol. 3 No 1, pp. 167-218.

Matsunaga, M. (2008), “Item parceling in structural equation modeling: a primer”, Communication Methods and Measures, Vol. 2 No. 4, pp. 260-293.

Mason, W. and Suri, S. (2012), “Conducting behavioral research on Amazon's Mechanical Turk", Behavior Research Methods, Vol. 44 No. 1, pp. 1-23. 
Maynard, M.T., Mathieu, J.E., Gilson, L.L., O’Boyle Jr, E.H. and Cigularov, K.P. (2013), "Drivers and outcomes of team psychological empowerment: a meta-analytic review and model test”, Organizational Psychology Review, Vol. 3 No. 2, pp. 101-137.

McAllister, D.J. and Bigley, G.A. (2002), "Work context and the definition of self: how organizational care influences organization-based self-esteem”, Academy of Management Journal, Vol. 45 No. 5, pp. 894-904.

Moorman, R.H. (1991), "Relationship between organizational justice and organizational citizenship behavior: do fairness perceptions influence employee citizenship?", Journal of Applied Psychology, Vol. 76 No. 6, pp. 845-855.

Nasser, F., and Takahashi, T. (2003), “The effect of using item parcels on Ad Hoc goodness-offit indexes in confirmatory factor analysis: an example using Sarason's reactions to tests", Applied Measurement in Education, Vol. 16 No. 1, pp. 75-97.

Pierce J.L. and Gardner, D.G. (2004), "Self-esteem within the work and organizational context: a review of the organization-based self-esteem literature", Journal of Management, Vol. 30 No. 5, pp. 91-622.

Pierce, J.L., Gardner, D.G., Cummings, L.L. and Dunham, R.B. (1989), “Organization-based self-esteem: construct definition, measurement, and validation", Academy of Management Journal, Vol. 32 No. 3, pp. 622-648.

Pigeon, M., Montani, F. and Boudrias, J.S. (2017), "How do empowering conditions lead to empowered behaviours? Test of a mediation model", Journal of Managerial Psychology, Vol. 32 No. 5, pp. 357-372. 
Podsakoff, P.M., MacKenzie, S.P. and Podsakoff, N.P. (2012), "Sources of method bias in social science research and recommendations on how to control it", Annual Review of Psychology, Vol. 63, pp. 539-569.

Porath, C.L., Spreitzer, G., Gibson, C. and Garnett, F.G. (2012), “Thriving at work: toward its measurement, construct validation, and theoretical refinement", Journal of Organizational Behavior, Vol. 33 No. 2, pp. 250-275.

Rushton, J.P. Brainerd, C.J., and Pressley, M. (1983), “Behavioral development and construct validity: the principle of aggregation", Psychological Bulletin, Vol. 94 No. 1, pp. 18-38.

Rupp, D.E., Shao, R., Jones, K.S. and Liao, H. (2014), "The utility of a multifoci approach to the study of organizational justice: a meta-analytic investigation into the consideration of normative rules, moral accountability, bandwidth-fidelity, and social exchange", Organizational Behavior and Human Decision Processes, Vol. 123 No. 2, pp. 159-185.

Seibert, S.E., Wang, G. and Courtright, S.H. (2011), “Antecedents and consequences of psychological and team empowerment in organizations: a meta-analytic review", Journal of Applied Psychology, Vol. 96 No. 5, pp. 981-1003.

Spreitzer, G.M. (1995), "Psychological empowerment in the workplace: dimensions, measurement, and validation", Academy of Management Journal, Vol. 38 No. 5, pp. 1442-1465.

Spreitzer, G.M. and Porath, C. (2014), "Self-determination as nutriment for thriving: building an integrative model of human growth at work", in Gagné, M. (Ed), The Oxford handbook of work engagement, motivation, and self-determination theory, Oxford University Press, New York, pp. 245-258. 
Spreitzer, G.M., Sutcliffe, K., Dutton, J., Sonenshein, S. and Grant, A.M. (2005), “A socially embedded model of thriving at work", Organization Science, Vol. 16 No 5, pp. 537-549.

Sweeney, P.D., and McFarlin, D.B. (1997), "Process and outcome: gender differences in the assessment of justice", Journal of Organizational Behavior, Vol. 18 No. 1, pp. 83-98.

Thibaut, J. and Walker, L. (1978), “A theory of procedure”, California Law Review, Vol. 66, pp. $541-566$.

Thomas, K.W. and Velthouse, B.A. (1990), "Cognitive elements of empowerment: an "interpretive" model of intrinsic task motivation", Academy of Management Review, Vol. 15 No. 4, pp. 666-681.

Walumbwa, F.O., Muchiri, M.K., Misati, E., Wu, C. and Meiliani, M. (2018), "Inspired to perform: a multilevel investigation of antecedents and consequences of thriving at work", Journal of Organizational Behavior, Vol. 39 No. 3, pp. 249-261.

Zapata-Phelan, C.P., Colquitt, J.A., Scott, B.A. and Livingston, B. (2009), "Procedural justice, interactional justice, and task performance: the mediating role of intrinsic motivation", Organizational Behavior and Human Decision Processes, Vol. 108 No. 1, pp. 93-105. 
Table 1

Means, Standard Deviations, Reliabilities, and Correlations

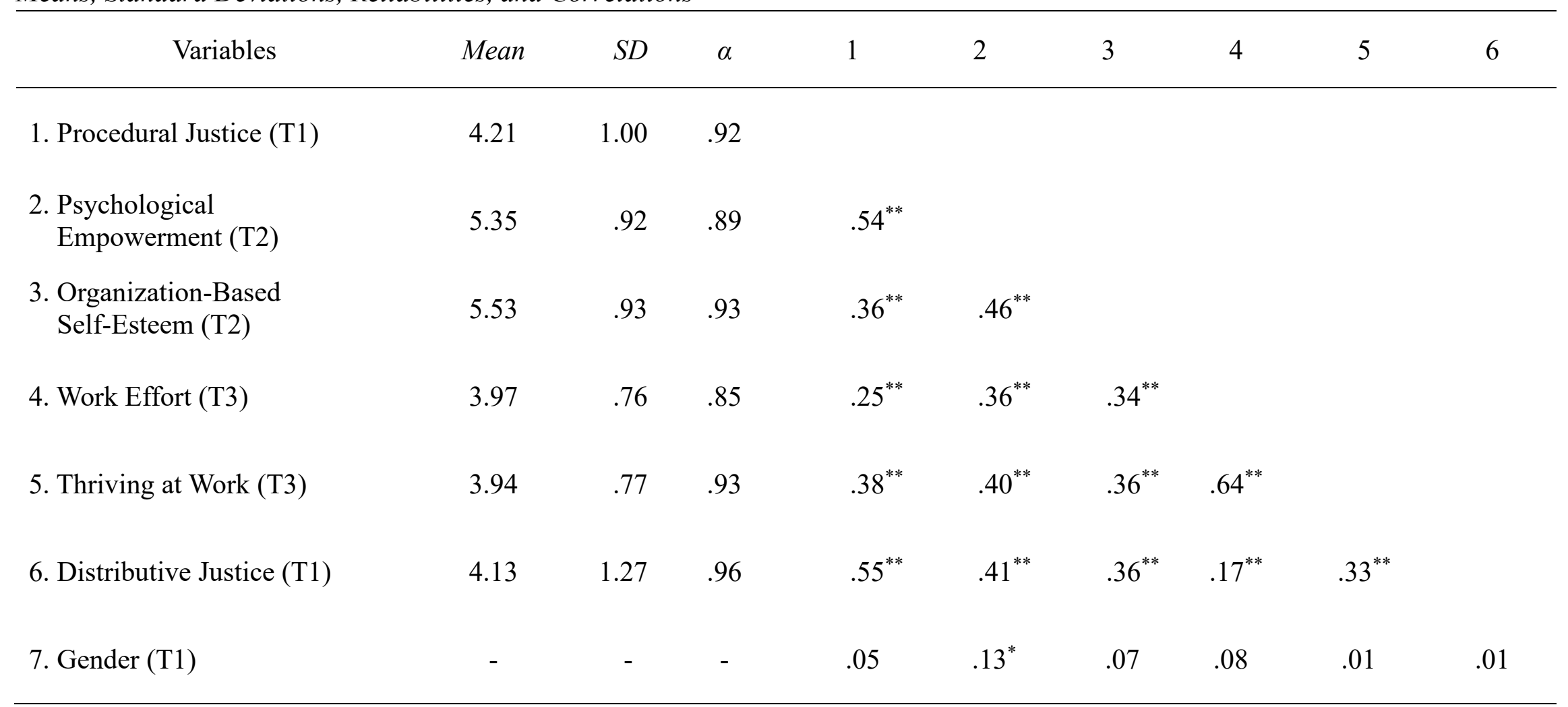

Notes: $n=346$. Distributive Justice and gender are control variables. Gender is coded men $=1$, women $=2$.

${ }^{* *} p<.01$.

${ }^{*} p<.05$. 
Table 2

Direct, Indirect, and Total Standardized Effects of Procedural Justice on Work Effort and Thriving in LISREL

\begin{tabular}{|c|c|c|c|c|c|}
\hline Effect from & & To & Direct Effects & Indirect Effects & Total Effect \\
\hline \multirow[t]{4}{*}{ Procedural Justice } & $\rightarrow$ & Psychological Empowerment & $.60^{* *}$ & & $.60^{* *}$ \\
\hline & $\rightarrow$ & Organization-Based Self-Esteem & $.31^{* *}$ & & $.31^{* *}$ \\
\hline & $\rightarrow$ & Work Effort & -.13 & $.35^{* *}$ & $.22^{* *}$ \\
\hline & $\rightarrow$ & Thriving at Work & .05 & $.32^{* *}$ & $.37^{* *}$ \\
\hline Psychological & $\rightarrow$ & Work Effort & $.43^{* *}$ & & $.43^{* *}$ \\
\hline Empowerment & $\rightarrow$ & Thriving at Work & $.45^{* *}$ & & $.45^{* *}$ \\
\hline Organization-Based & $\rightarrow$ & Work Effort & $.32^{* *}$ & & $.32^{* *}$ \\
\hline Self-Esteem & $\rightarrow$ & Thriving at Work & $.16^{* *}$ & & $.16^{* *}$ \\
\hline
\end{tabular}

Notes: $n=346 .{ }^{* *} p<.01$. 


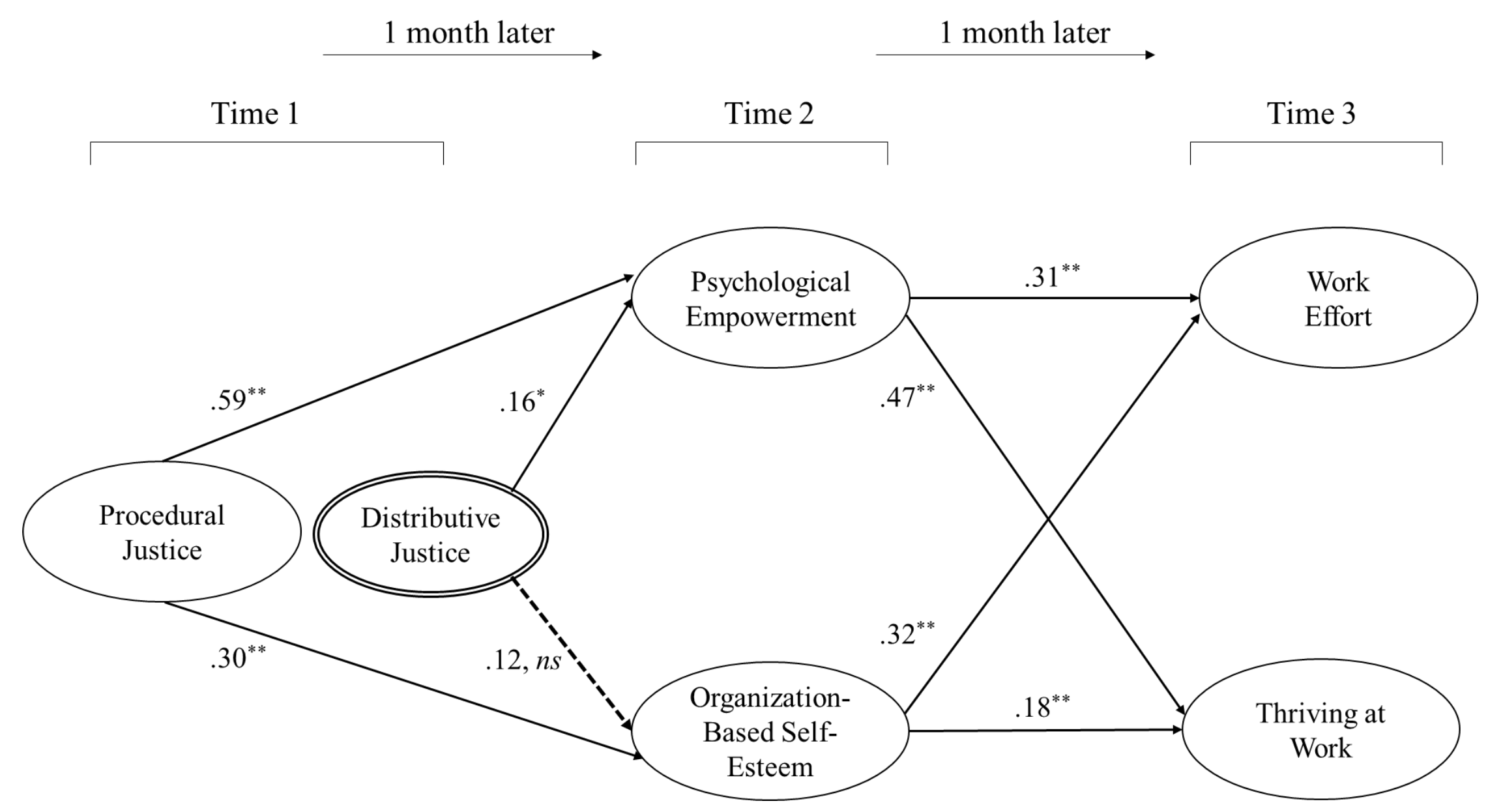

Figure 1. Structural equation model with standardized coefficients

Notes: $n=346$. Measurement model and disturbance error effects are not indicated to simplify the presentation. All paths in the hypothesized structural model are significant $(p<.01)$. The double circle indicates the control variable. The broken line indicates a non-significant path between the control variable, Distributive Justice, and Organization-Based Self-Esteem. ${ }^{* *} p<.01 ;{ }^{*} p<.05$. 
1 month later

Time 1

\section{1 month later}

Time 2
Time 3

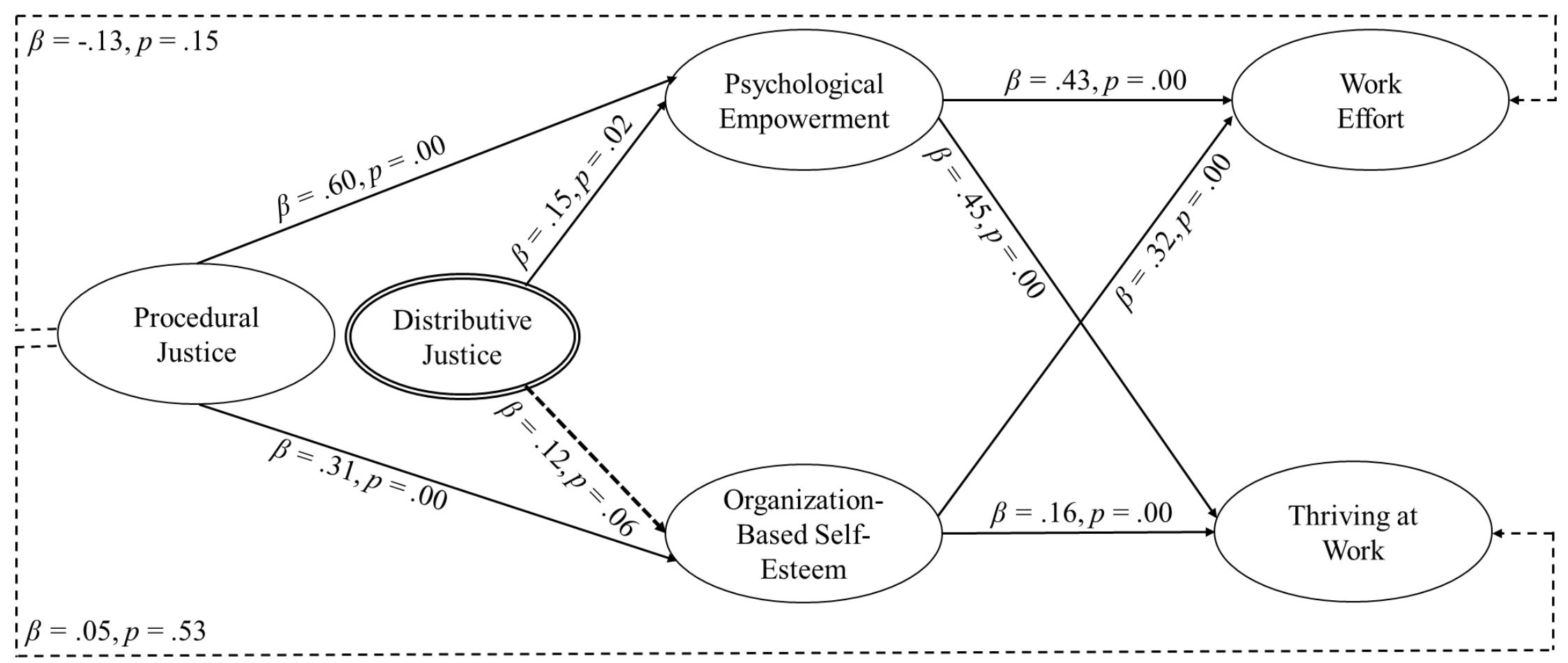

Figure 2. Alternative structural equation model with standardized coefficients

Notes: $n=346$. The double circle indicates the control variable. All hypothesized paths in the structural model are represented as solid lines and are significant $(p<.01)$. Broken lines represent other paths and were nonsignificant. 